$\xi=$ 잘

\title{
Denture Hygiene: The Sharing Responsibility
}

\author{
Wael M. Zakaria ${ }^{1}$, Yasser S. Almunajem ${ }^{2}$, Hadeel M. Alnowaiser ${ }^{3}$ \\ ${ }^{1}$ Department of Prosthetic Dental Sciences, College of Dentistry, Qassim University, Saudi Arabia \\ ${ }^{2}$ Intern, College of Dentistry, Qassim University, Saudi Arabia \\ *Corresponding author E-mail: dr.wael.zakaria@qudent.edu.sa
}

\begin{abstract}
Background: Regular and effective denture hygiene among complete denture patients has a great effect on preventing various oral lesions based on appropriate hygiene measures given by the prosthodontist.

Objective: The current study aimed to analyze the denture hygiene behaviors among complete denture wearers at the Dental Hospital in Qassim University, KSA.

Subjects and Methods: In the current study, 91 complete denture wearers (61 males and 30 females) attending the dental clinics at Qassim University in Saudi Arabia were included. A questionnaire was used which mainly focuses on evaluating the participants regarding the complete denture hygiene and their behaviors and ability to clean the denture at appropriate intervals.

Results: A total of 91 patients were interviewed. Their age ranges between 35 to 85 years. (92.3\%) of the participants received instructions about cleaning and care of their denture. $78 \%$ of these instructions were verbal. (51.6\%) of complete denture wearers used water and a toothbrush to clean their denture. Most of the patients $(76.62 \%)$ removed their denture at night before sleep while less number (26.37\%) did not. With regard to routine follow up, $73.6 \%$ of participants never attend any visit.

Conclusion: Improve the awareness of complete denture patients towards the importance of maintaining their denture hygiene and the importance of regular periodic visit is a sharing responsibility between the prosthodontist and the patients.
\end{abstract}

Keywords: Dentures; Hygiene; Brushing; Instructions; Follow-Up

\section{Introduction}

Complete dentures are used for replacing the entire set of lost tooth in the dental arch so as to replace the esthetic and functional conditions of the patients and to maintain an odor-free appliance (Guggenheimer, Moore et al. 2000).

Placement of denture in the oral cavity produces profound changes of the oral environment that may have an adverse effect on the integrity of the oral tissues (Zissis, Yannikakis et al. 2006).

Rehabilitative treatment is successful only when patients are motivated and aware of correct prosthesis use and hygiene. The quality of the denture fitting surface, occlusal relations, denture age and hygiene are important factors contributing to the prevalence of oral mucosal lesions associated with denture use (Dikbas, Koksal et al. 2006).

It is mistakenly believed that trials to educate and motivate the complete denture patients are wasted efforts, and that these patients are edentulous because they did not properly maintain their teeth and any preventive program will be poorly received (Hashiguchi, Nishi et al. 2009).

The initial recommendations to patients refer to the need for periodical visits to the dentist for maintenance purposes and additional explanations regarding denture cleansing and wearing habits. The patient's correct cleansing of complete dentures is essential to prevent staining of dentures (Shay 2000) and them becoming coated with a biofilm, which could damage the adjacent mucosa and cause systemic diseases (Sumi, Miura et al. 2002). Incorrect habits, such as wearing complete dentures at night (Markovic, Puskar et al. 1999) and incorrect cleansing have proven to be closely associated with the prevalence of denture-related stomatitis (Khasawneh and al-Wahadni 2002).

The strong correlation between unsatisfactory cleaning and the prevalence of Candida had been found. To minimize the prevalence of denture stomatitis, the dentist must instruct the patient in removing complete dentures 6 to 8 hours per day (Peracini, Andrade et al. 2010).

Complete dentures can be cleaned mechanically (brushing and ultrasonic device) and by chemical methods (alkaline peroxide and hypochlorite, acids, enzymes and disinfectants). Among these, brushing with conventional and specific dentifrices is the most common method applied to routine denture biofilm control and has been proven effective (Paranhos, Silva-Lovato et al. 2007). Soap, as an auxiliary hygiene agent, is an accessible abrasive-free product and has been claimed as effective against anaerobic microorganisms and yeasts and stains (Salles, Macedo et al. 2007). Studies have indicated that the combination of coconut soap with hypochlorite is an effective cleansing method (Barnabe, de Mendonca Neto et al. 2004).

Awareness is the first step of any change, awareness of the patient regarding denture staining \& its effect on the surrounding structures depends on either lack of knowledge or ignorance. So it is first important to evaluate the percentage of awareness of complete denture patient regarding denture hygiene.

Using a specific questionnaire, the aim of this study was to analyze the denture hygiene behaviors of complete denture patients at the Dental Hospital in Qassim University, KSA. 


\section{Materials and methods}

In this study a total of 91 complete denture wearers (61 males and 30 females) attending the Dental hospital at Qassim University in Saudia Arabia was included. The study was approved by the Ethical Committee in College of Dentistry, Qassim University and all participants gave their written informed consent.

A questionnaire was used which mainly focuses on evaluating the participants regarding the complete denture hygiene and their behaviors and ability to clean the denture at appropriate intervals. The questionnaire contained demographic information like name, age, gender, period of wearing, and other questions as denture instructions received, mode of receiving them, frequency of cleaning, materials used for cleaning (Peracini, Andrade et al. 2010; Milward, Katechia et al. 2013).

Data were gathered, tabulated and statistically analyzed. SPSS (Statistical Program for Social Sciences) for Window (SPSS Inc. version 20) was used for data analysis, from which descriptive statistics were generated.

\section{Result}

A total of 91 patients were interviewed. The age of the participants range was 35 to 85 years, and they were divided into 5 groups according to their age. The most common age group was 56-65 years $(37.4 \%)$. The age distribution is shown in table (1).

Table 1: Age Distribution of Patients

\begin{tabular}{|c|c|c|c|c|c|c|}
\hline \multirow{2}{*}{ Age Group } & \multicolumn{2}{|c|}{ Male } & \multicolumn{2}{c|}{ Female } & \multicolumn{2}{c|}{ Total } \\
\cline { 2 - 7 } & No & \% & No & \% & No & \% \\
\hline $\mathbf{3 5 - 4 5}$ & 8 & $13.1 \%$ & 3 & $10.0 \%$ & 11 & $12.1 \%$ \\
\hline $\mathbf{4 6 - 5 5}$ & 17 & $27.9 \%$ & 6 & $20.0 \%$ & 23 & $25.3 \%$ \\
\hline $\mathbf{5 6 - 6 5}$ & 24 & $39.3 \%$ & 10 & $33.3 \%$ & 34 & $\mathbf{3 7 . 4 \%}$ \\
\hline $\mathbf{6 6 - 7 5}$ & 9 & $14.8 \%$ & 9 & $30.0 \%$ & 18 & $19.8 \%$ \\
\hline $\mathbf{7 6 - 8 5}$ & 3 & $4.9 \%$ & 2 & $6.7 \%$ & 5 & $5.5 \%$ \\
\hline Total & 61 & $100.0 \%$ & 30 & $100.0 \%$ & 91 & $100.0 \%$ \\
\hline
\end{tabular}

The period of wearing the existing dentures shows that $25.27 \%$ patients used their denture less than 6 months, $28.5 \%$ more than 2 years and $46 \%$ from 6 months to 2 years.

Most of the participants (92.3\%) received instructions about cleaning and care of their denture, $78 \%$ of them received this instruction verbally.

All the patients cleaned their complete dentures. $37.3 \%$ once per day, $(30.75 \%)$ twice per day while $(8.79 \%)$ more than 3 times per day.

The majority of complete denture wearers $(51.6 \%)$ used water and a toothbrush to clean their denture. (76.62\%) of patients removed their denture at night before sleep while less number (26.37\%) did not.

With regard to routine follow up visit to the dentist for regular denture examination, $73.6 \%$ of participants never attended any visit.

The detailed results obtained for various factors considered are as tabulated in table (2).

\section{Discussion}

Care of dentures and the mucosal tissues of the edentulous mouth are important for overall health, especially in older persons. Unclean dentures causing or contributing to oral mucosal disease and / or impairment in eating, therefore, may have a more profound effect on a frail elder than younger, healthier person.

In order to avoid any other infections or diseases, the denture must be maintained in a proper condition by cleaning it often (Laurina and Soboleva 2006).

The present study consists of a sample of 91 completely edentulous patients (67\% male and $33 \%$ female) who used their complete denture for at least 6 months comfortably and with satisfaction.
To instruct the wearers of complete denture about proper denture hygiene is one of the responsibilities of Prosthodontist. However, it has been observed that the majority of denture wearers does not receive idea about the cleanliness and hygiene of dentures as mentioned in the result obtained by (Peracini, Andrade et al. 2010) , (Dikbas, Koksal et al. 2006), (Hoad-Reddick, Grant et al. 1990) and (Marchini, Tamashiro et al. 2004) who found that $(51.89 \%),(82.9 \%),(86.3 \%)$ and $(77.5 \%)$, respectively, of the participants did not receive proper denture cleaning instructions from their dentists. This may be due to denture wearers 'negligence as well as dentists who give insufficient instruction to their patients about denture cleaning methods or neglect spending time on this issue (Nevalainen, Narhi et al. 1997).

Table 2: Distribution of Denture Hygiene Parameters among the Patients

\begin{tabular}{|c|c|c|c|c|c|c|c|}
\hline \multirow{2}{*}{\multicolumn{2}{|c|}{ Parameters }} & \multicolumn{2}{|c|}{ Male } & \multicolumn{2}{|c|}{ Female } & \multicolumn{2}{|c|}{ Total } \\
\hline & & \multirow{2}{*}{$\begin{array}{l}\text { No } \\
15\end{array}$} & \multirow{2}{*}{$\begin{array}{c}\% \\
24.6 \%\end{array}$} & \multirow{2}{*}{$\begin{array}{c}\text { No } \\
8\end{array}$} & \multirow{2}{*}{$\begin{array}{c}\% \\
26.7 \%\end{array}$} & \multirow{2}{*}{$\begin{array}{l}\text { No } \\
23\end{array}$} & \multirow{2}{*}{\begin{tabular}{|c|}
$\%$ \\
$25.27 \%$
\end{tabular}} \\
\hline \multirow{4}{*}{$\begin{array}{c}\text { Period of } \\
\text { wearing }\end{array}$} & $\begin{array}{c}\text { less than } 6 \\
\text { months }\end{array}$ & & & & & & \\
\hline & $\begin{array}{c}6 \text { months - } 1 \\
\text { year }\end{array}$ & 12 & $19.7 \%$ & 9 & $30.0 \%$ & 21 & $23 \%$ \\
\hline & 1-2 years & 12 & $19.7 \%$ & 9 & $30.0 \%$ & 21 & $23 \%$ \\
\hline & $\begin{array}{c}\text { more than } 2 \\
\text { years }\end{array}$ & 22 & $36.1 \%$ & 4 & $13.3 \%$ & 26 & $28.5 \%$ \\
\hline \multirow{2}{*}{$\begin{array}{c}\text { Instructions } \\
\text { received }\end{array}$} & Yes & 58 & $95.1 \%$ & 26 & $86.7 \%$ & 84 & $92.3 \%$ \\
\hline & No & 3 & $4.9 \%$ & 4 & $13.3 \%$ & 7 & $7.6 \%$ \\
\hline \multirow{3}{*}{$\begin{array}{c}\text { Form of } \\
\text { instructions }\end{array}$} & verbal only & 58 & $100.0 \%$ & 13 & $50.0 \%$ & 71 & $78 \%$ \\
\hline & written only & 0 & $0.0 \%$ & 7 & $26.9 \%$ & 7 & $7.69 \%$ \\
\hline & $\begin{array}{l}\text { both verbal } \\
\text { and written }\end{array}$ & 0 & $0.0 \%$ & 6 & $23.1 \%$ & 6 & $6.59 \%$ \\
\hline \multirow{2}{*}{$\begin{array}{l}\text { Denture } \\
\text { cleaning }\end{array}$} & Yes & 61 & $100.0 \%$ & 30 & $100.0 \%$ & 91 & $100 \%$ \\
\hline & No & 0 & $0.0 \%$ & 0 & $0.0 \%$ & 0 & $0 \%$ \\
\hline \multirow{4}{*}{$\begin{array}{l}\text { Frequency } \\
\text { of cleaning }\end{array}$} & Once & 24 & $39.3 \%$ & 10 & $33.3 \%$ & 34 & $37.3 \%$ \\
\hline & Twice & 19 & $31.1 \%$ & 9 & $30.0 \%$ & 28 & $30.7 \%$ \\
\hline & three times & 14 & $23.0 \%$ & 7 & $23.3 \%$ & 21 & $23 \%$ \\
\hline & $\begin{array}{l}\text { more than } \\
\text { three times }\end{array}$ & 4 & $6.6 \%$ & 4 & $13.3 \%$ & 8 & $8.79 \%$ \\
\hline \multirow{4}{*}{$\begin{array}{c}\text { Method } \\
\text { of cleaning }\end{array}$} & $\begin{array}{l}\text { Water and } \\
\text { toothbrush }\end{array}$ & 40 & $65.6 \%$ & 7 & $23.3 \%$ & 47 & $51.6 \%$ \\
\hline & $\begin{array}{c}\text { Water and } \\
\text { soap + } \\
\text { toothbrush }\end{array}$ & 9 & $14.8 \%$ & 13 & $43.3 \%$ & 22 & $24.1 \%$ \\
\hline & $\begin{array}{l}\text { Water and } \\
\text { dentifrice + } \\
\text { toothbrush }\end{array}$ & 12 & $19.7 \%$ & 10 & $33.3 \%$ & 22 & $24.1 \%$ \\
\hline & $\begin{array}{l}\text { Other } \\
\text { methods }\end{array}$ & 0 & 0 & 0 & 0 & 0 & 0 \\
\hline \multirow{2}{*}{$\begin{array}{c}\text { Remove at } \\
\text { night before } \\
\text { sleep }\end{array}$} & Yes & 43 & $70.5 \%$ & 24 & $80.0 \%$ & 67 & $73.62 \%$ \\
\hline & No & 18 & $29.5 \%$ & 6 & $20.0 \%$ & 24 & $26.37 \%$ \\
\hline \multirow{5}{*}{$\begin{array}{c}\text { Routine } \\
\text { follow up } \\
\text { examination }\end{array}$} & $\begin{array}{c}\text { once every } 6 \\
\text { months }\end{array}$ & 7 & $11.5 \%$ & 0 & $0.0 \%$ & 7 & $7.7 \%$ \\
\hline & once a year & 7 & $11.5 \%$ & 2 & $6.7 \%$ & 9 & $9.9 \%$ \\
\hline & $\begin{array}{c}\text { once every } 2 \\
\text { years }\end{array}$ & 1 & $1.6 \%$ & 5 & $16.7 \%$ & 6 & $6.6 \%$ \\
\hline & others & 1 & $1.6 \%$ & 1 & $3.3 \%$ & 2 & $2.2 \%$ \\
\hline & Never & 45 & $73.8 \%$ & 22 & $73.3 \%$ & 67 & $73.6 \%$ \\
\hline
\end{tabular}


Marchini, Tamashiro et al. 2004 established in their study a significant relationship between the presence of denture stomatitis and self-reported lack of instructions regarding oral care. Moreover, they revealed a significant relationship between the presence of hyperplasia and self-reported lack of instruction concerning denture cleansing.

These results are not in agreement with our study' result as $(92.3 \%)$ of the patients received guidance from their Prosthodontist, they are oriented about denture care, nocturnal removal and importance of periodic check-up

Milward, Katechia et al. 2013 demonstrated an association between the level of cleanliness of participants and the form in which instructions and advice were given to them regarding cleaning and caring for their denture. Those participants who stated they had received both verbal and written instructions had better levels of denture cleanliness when compared with those only receiving verbal instructions). These results are not in agreement with our study' result as (78\%) of patients, received guidance from their Prosthodontist, took it verbally.

All of the study population said they cleaned their dentures at least once a day, even those who didn't receive instruction about denture hygiene by the prosthodontist $(7.6 \%)$. Those patients $(7.6 \%)$ might receive some guidance and oriented about aspect of denture care from other resources such as parents, colleagues, website or others. Nevalainen, Narhi et al. 1997 suggested that patients' age of 80 years or more could indicate inefficient cleaning due to commonplace limitations such as a reduction in visual acuity and manual dexterity. However, the majority of participants in this study ranged from 35 to 75 years (94.5\%) and they reported having no difficulty in cleaning their dentures.

These results agree with those of Peracini, Andrade et al. 2010 (99.06\%), Marchini, Tamashiro et al. 2004 (98.7\%), Nevalainen, Narhi et al. 1997 (96.0\%) and de Castellucci Barbosa, Ferreira et al. 2008 (98.0\%). Hoad-Reddick, Grant et al. 1990) and Dikbas, Koksal et al. 2006 showed that only $(79.1 \%)$ of a sample of 233 patients and $(70.0 \%)$ of a sample of 234 patients, respectively, cleaned their dentures at least once a day.

Nearly half of the subjects in Saha, Dutta et al. 2014 study cleaned their dentures daily once. In contrast to Saha et al only (37.3\%) patients in the current study cleaned their denture daily once. The difference may be large sample and more awareness for denture hygiene in the Saha et al study group.

In this study, all patients (100\%) used brushing (mechanical method) for denture cleansing. Similar results were obtained in previous studies by Peracini, Andrade et al. 2010 (100\%) and Jeganathan, Payne et al. 1997 (97\%). Other studies have reported that $80.1 \%$ (Coelho, Sousa et al. 2004), $79.7 \%$ (Marchini, Tamashiro et al. 2004), 57.1\% (Kulak-Ozkan, Kazazoglu et al. 2002) and 40.59\% (Dikbas, Koksal et al. 2006) of patients brushed their dentures as the cleaning method of choice.

The majority of the patients in the present study (51.6\%) reported brushing only with water. $(24.1 \%)$ used soap while $(24.1 \%)$ used toothpaste with the toothbrush. No patient in the present study reported the use of immersion in denture cleaning solutions. In previous studies, de Castellucci Barbosa, Ferreira et al. 2008 found $8 \%$ and Ozcan, Kulak et al. 2004 found $17.1 \%$ of those interviewed used only water to clean their prostheses, whereas the most commonly used method was brushing with toothpaste and a toothbrush, which is not in agreement with the result of this study. Mechanical methods, such as toothbrushes, are recommended for routine cleaning. However, they may lead to surface abrasion, which is undesirable for aesthetic and biological reasons (Tanoue, Matsumura et al. 2000). Denture pigmentation and abrasions are associated with toothpaste and toothbrush use (Peltola, Raustia et al. 1997). Dentifrice has the advantage of being simple to use and relatively inexpensive. However, if used with an improper brushing technique, dentifrice can damage the prosthesis material (Dikbas, Koksal et al. 2006) due to the potential abrasive wear of the denture material (Jagger and Harrison 1995). Brushing with toothpaste may make denture surfaces rougher, which increases the accumulation of plaque and reduces the shine of complete denture surfaces (Tanoue, Matsumura et al. 2000). In addition, brushing alone, with or without dentifrice, is an inadequate approach for controlling denture plaque (Shay 2000) and mechanical methods are not normally sufficient to remove the microorganisms that colonize resinous materials (Barnabe, de Mendonca Neto et al. 2004).

Data analysis in this study showed that $(73.62 \%)$ of the patients removed their dentures at night. Contrasting results were obtained in previous studies in which $58.49 \%$ (Peracini, Andrade et al. 2010) 41.5\% (Dikbas, Koksal et al. 2006) and 64\% (de Castellucci Barbosa, Ferreira et al. 2008) of patients, respectively, did not remove their dentures at bedtime. Baran and Nalcaci 2009 also showed that $55.2 \%$ of the patients slept with their dentures. Marcus, Joshi et al. 1996 found that nearly one third of the participants in their study slept with both dentures, and $12 \%$ slept with the lower denture only.

The use of dentures during the day by the patients might result in the accumulation of biofilm on their surface (Hoad-Reddick, Grant et al. 1990; Marchini, Tamashiro et al. 2004). Thus the continuous use increases the prevalence of denture-induced stomatitis, which has the biofilm as its main etiological factor. According to Zissis, Yannikakis et al. 2006 higher prevalence of denture stomatitis was reported in patients who persistently wore dentures (day and night). Similar result was reported by Jeganathan, Payne et al. 1997 who reported that denture-induced stomatitis was more prevalent in patients with persistent use of the dentures (61/\%)when compared to controls with healthy mucosa.

A common misconception by many complete denture wearers is that once provided with the satisfied prosthesis, no further oral examinations are required. Results show $(73.6 \%)$ of participants has never visited the dentist for routine examinations. Individuals' reasoning behind this may be that their comfortable dentures are not susceptible to the problem of caries, inflammation or any dental pathosis neglecting the effect of the prosthesis on the oral mucosa. Also, they thought that any type of pain originates from the denture could be solved by removing the prosthesis form the oral cavity and resting the tissue.

According to the study results of Kalaignan 2017 (56.7\%) of previous denture wearers did not receive denture hygiene instructions and $43.3 \%$ were educated by their previous dentists. This however does not signify that all $43.3 \%$ of patients were compliant and practiced denture cleaning thoroughly as some still presented with unhygienic dentures and complained of facing difficulties in cleaning dentures. This could be due to the patient's attitude and stance toward dental care and inability to maintain a denture cleaning routine in the long run.

Individuals with complete denture should have routine dental examinations every 6 to 12 months as part of their denture aftercare, to allow their denture bearing area to be checked and to examine their overall oral health. These examinations also allow the dentist to monitor the individual's denture hygiene and present the opportunity for the dentist to reinforce messages on denture hygiene (Ribeiro, Pavarina et al. 2009; Milward, Katechia et al. 2013).

\section{Conclusion}

Improve the awareness of complete denture patients towards the importance of maintaining their denture hygiene and the importance of regular periodic visit is a sharing responsibility between the prosthodontist and the patients.

\section{References}

[1] Baran, I. and R. Nalcaci (2009). "Self-reported denture hygiene habits and oral tissue conditions of complete denture wearers." $\begin{array}{lll}\text { Arch Gerontol } & \text { Geriatr } & \text { 237-241. }\end{array}$ https://doi.org/10.1016/j.archger.2008.08.010.

[2] Barnabe, W., T. de Mendonca Neto, et al. (2004). "Efficacy of sodium hypochlorite and coconut soap used as disinfecting agents in the reduction of denture stomatitis, Streptococcus mutans and 
Candida albicans." J Oral Rehabil 31(5): 453-459. https://doi.org/10.1111/j.1365-2842.2004.01254.x.

[3] Coelho, C. M., Y. T. Sousa, et al. (2004). "Denture-related oral mucosal lesions in a Brazilian school of dentistry." J Oral Rehabil 31(2): 135-139. https://doi.org/10.1111/j.1365-2842.2004.01115.x.

[4] de Castellucci Barbosa, L., M. R. Ferreira, et al. (2008). "Edentulous patients' knowledge of dental hygiene and care of prostheses." $\quad$ Gerodontology 25(2): $\quad 99-106$ https://doi.org/10.1111/j.1741-2358.2007.00190.x.

[5] Dikbas, I., T. Koksal, et al. (2006). "Investigation of the cleanliness of dentures in a university hospital." Int J Prosthodont 19(3): 294298.

[6] Guggenheimer, J., P. A. Moore, et al. (2000). "Insulin-dependent diabetes mellitus and oral soft tissue pathologies: II. Prevalence and characteristics of Candida and Candidal lesions." Oral Surg Oral Med Oral Pathol Oral Radiol Endod 89(5): 570-576. https://doi.org/10.1067/moe.2000.104477.

[7] Hashiguchi, M., Y. Nishi, et al. (2009). "Bactericidal efficacy of glycine-type amphoteric surfactant as a denture cleaner and its influence on properties of denture base resins." Dent Mater J 28(3): 307-314. https://doi.org/10.4012/dmj.28.307.

[8] Hoad-Reddick, G., A. A. Grant, et al. (1990). "Investigation into the cleanliness of dentures in an elderly population." J Prosthet Dent 64(1): 48-52. https://doi.org/10.1016/0022-3913(90)90152-3.

[9] Jagger, D. C. and A. Harrison (1995). "Denture cleansing--the best approach." $\quad \mathrm{Br} \quad$ Dent J 178(11): 413-417. https://doi.org/10.1038/sj.bdj.4808788.

[10] Jeganathan, S., J. A. Payne, et al. (1997). "Denture stomatitis in an elderly edentulous Asian population." J Oral Rehabil 24(6): 468472. https://doi.org/10.1046/j.1365-2842.1997.00523.x.

[11] Kalaignan, S. P. (2017). "Level of Denture Hygiene Education and the Quality of Denture Fabricated By Dental Students." Acta Scientific Dental Sciences 1(1): 04-08.

[12] Khasawneh, S. and A. al-Wahadni (2002). "Control of denture plaque and mucosal inflammation in denture wearers." J Ir Dent Assoc 48(4): 132-138.

[13] Kulak-Ozkan, Y., E. Kazazoglu, et al. (2002). "Oral hygiene habits, denture cleanliness, presence of yeasts and stomatitis in elderly people." J Oral Rehabil 29(3): 300-304. https://doi.org/10.1046/j.1365-2842.2002.00816.x.

[14] Laurina, L. and U. Soboleva (2006). "Construction faults associated with complete denture wearers' complaints." Stomatologija 8(2) 61-64.

[15] Marchini, L., E. Tamashiro, et al. (2004). "Self-reported denture hygiene of a sample of edentulous attendees at a University denta clinic and the relationship to the condition of the oral tissues." Gerodontology 21(4): 226-228. https://doi.org/10.1111/j.17412358.2004.00026.x.

[16] Marcus, P. A., A. Joshi, et al. (1996). "Complete edentulism and denture use for elders in New England." J Prosthet Dent 76(3): 260 266. https://doi.org/10.1016/S0022-3913(96)90169-9.

[17] Markovic, D., T. Puskar, et al. (1999). "Denture cleaning techniques in the elderly affecting the occurrence of dentureinduced stomatitis." Med Pregl 52(1-2): 57-61.

[18] Milward, P., D. Katechia, et al. (2013). "Knowledge of removable partial denture wearers on denture hygiene." Br Dent J 215(10): E20. https://doi.org/10.1038/sj.bdj.2013.1095.

[19] Nevalainen, M. J., T. O. Narhi, et al. (1997). "Oral mucosal lesions and oral hygiene habits in the home-living elderly." J Oral Rehabil 24(5): 332-337. https://doi.org/10.1046/j.1365-2842.1997.d01 298.x.

[20] Ozcan, M., Y. Kulak, et al. (2004). "The attitude of complete denture wearers towards denture adhesives in Istanbul." J Oral Rehabil 31(2): 131-134. https://doi.org/10.1046/j.0305182X.2003.01224.X.

[21] Paranhos, H. F., C. H. Silva-Lovato, et al. (2007). "Effects of mechanical and chemical methods on denture biofilm accumulation." J Oral Rehabil 34(8): 606-612. https://doi.org/10.1111/j.1365-2842.2007.01753.x.

[22] Peltola, M. K., A. M. Raustia, et al. (1997). "Effect of complete denture renewal on oral health--a survey of 42 patients." J Oral Rehabil 24(6): 419-425. https://doi.org/10.1046/j.13652842.1997.00510.x.

[23] Peracini, A., I. M. Andrade, et al. (2010). "Behaviors and hygiene habits of complete denture wearers." Braz Dent J 21(3): 247-252. https://doi.org/10.1590/S0103-64402010000300013.

[24] Ribeiro, D. G., A. C. Pavarina, et al. (2009). "Effect of oral hygiene education and motivation on removable partial denture wearers: longitudinal study." Gerodontology 26(2): 150-156. https://doi.org/10.1111/j.1741-2358.2008.00272.x.
[25] Saha, A., S. Dutta, et al. (2014). "A survey assessing modes of maintaining denture hygiene among elderly patients." J Int Soc Prev Community Dent 4(3): 145-148. https://doi.org/10.4103/22310762.142007 .

[26] Salles, A. E., L. D. Macedo, et al. (2007). "Comparative analysis of biofilm levels in complete upper and lower dentures after brushing associated with specific denture paste and neutral soap." Gerodontology 24(4): 217-223. https://doi.org/10.1111/j.17412358.2007.00169.x.

[27] Shay, K. (2000). "Denture hygiene: a review and update." J Contemp Dent Pract 1(2): 28-41. https://doi.org/10.1111/j.17412358.2002.00025.X.

[28] Sumi, Y., H. Miura, et al. (2002). "Colonization of denture plaque by respiratory pathogens in dependent elderly." Gerodontology 19(1): 25-29.

[29] Tanoue, N., H. Matsumura, et al. (2000). "Wear and surface roughness of current prosthetic composites after toothbrush/dentifrice abrasion." J Prosthet Dent 84(1): 93-97. https://doi.org/10.1067/mpr.2000.107560.

[30] Zissis, A., S. Yannikakis, et al. (2006). "Comparison of denture stomatitis prevalence in 2 population groups." Int J Prosthodont 19(6): 621-625. 